\title{
Re-visitando la Hegemonía conservadora: raza y política en Cartagena (Colombia), 1885-1930*
}

\section{Resumen}

Entre 1885 y 1930, una serie de gobiernos de orientación conservadora ejercieron el poder político en Colombia. Investigaciones previas sobre este periodo, conocido como la Hegemonía conservadora, coinciden en pintar un cuadro marcado por la escasez de liderazgos afrodescendientes. Este artículo, a partir de la trayectoria política y profesional construida por sectores negros y mulatos en el Caribe colombiano, pretende ofrecer una nueva aproximación sobre el cuadro previamente mencionado. El artículo muestra que durante ese periodo un grupo de profesionales y políticos de este origen racial accedieron a espacios académicos y políticos a través de los cuales adelantaron debates sobre raza, política y educación. Concluyo que estos sectores, para defender los espacios de representación política e intelectual que lograron conquistar, articularon un discurso que cuestionó la supuesta inferioridad racial de los afrodescendientes que varios miembros de la élite blanca intentaron imponer durante la Hegemonía conservadora.

Palabras claves: Cartagena, Hegemonía conservadora, negros, raza, política.

Referencias para este artículo: FLÓREZ BOLÍVAR, Francisco Javier (2018). "Re-visitando la Hegemonía conservadora: raza y política en Cartagena (Colombia), 1885-1930”. En Anuario de Historia Regional y de las Fronteras. 23 (1). pp. 93-120.

Francisco Javier Flórez Bolívar: Doctor en Historia de la Universidad de Pittsburgh, Estados Unidos (2016). Magíster en Historia en la Universidad de Pittsburgh, Estados Unidos (2011). Historiador de la Universidad de Cartagena, Colombia (2004). Miembro del grupo de investigación Historia Económica, Política y Social del Programa de Historia de la Universidad de Cartagena, Colombia, donde labora como docente y dirige la revista El Taller de la Historia. Recientemente, coeditó una colección de ensayos titulada Los desterrados del paraíso. Raza, pobreza y cultura en Cartagena de Indias (Barranquilla/ Colombia: editorial Maremágnum, 2015). Código ORCID: https://orcid.org/0000-0002-9095-7433. Correo electrónico: fflorezb1@unicartagena.edu.co o pachohistory18@hotmail.com.

\footnotetext{
* Este artículo sintetiza algunos de los hallazgos del proyecto de investigación Beyond the White Republic: Afro-descendant Elites, Race and Citizenship in Cartagena (Colombia) 1903-1945, que recibió financiación de Fulbright-Colombia, LASPAU: Academic and Professional Programs for the Americas, el Departamento de Historia, y el Centro de Estudios Latinoamericanos de la Universidad de Pittsburgh en Estados Unidos.
} 


\title{
Re-visiting the Conservative Hegemony: Race and Politics in Cartagena (Colombia), 1885-1930
}

\begin{abstract}
Between 1885 and 1930, several conservatively-oriented governments controlled the political power in Colombia. Previous researches about this period, which it is known as the Conservative Hegemony, coincide in revealing the absence of Afrodescendant leaderships. By looking at the political and professional trajectories of a group of black and darker-skinned people, this article proposes a novel approach to the previously mentioned picture. The article shows that during this period a significant group of Afro-descendants rose to political and intellectual positions through which they conducted debates about race, politics and education. I conclude that Afro-Colombians, by defending the political representation they had achieved, articulated an alternative discourse to the ideas on the alleged natural inferiority of Afro-descendants that some members of the white elite attempted to impose during the conservative hegemony.
\end{abstract}

Keywords: Cartagena, Conservative Hegemony, Blacks, Race, Politics.

\section{Re-visitando a hegemonia conservadora: raça e política em Cartagena (Colômbia), 1885-1930}

\section{Resumo}

Entre 1885 e 1930, uma série de governos de orientação conservadora exerceram o poder político na Colômbia. Pesquisas anteriores sobre esse período, que é conhecido como Hegemonia Conservadora, coincidem em sugerir um quadro marcado pela ausência de lideranças afrodescendentes. Este artigo, ao analisar as trajetórias políticas e profissionais de um grupo de negros e mulatos, propõe uma nova abordagem ao quadro anteriormente mencionado. O artigo mostra que durante este periodo um grupo significativo de afrodescendentes ascenderam a posições politicas e intelectuais através das quais eles conduziram debates sobre raça, política e educação. Concluo que os afro-colombianos, defendendo os espaços de poder que alcançaram, articularam um discurso alternativo às ideias sobre a alegada inferioridade natural dos afrodescendentes que alguns membros da elite branca tentaram impor durante a hegemonia conservadora.

Palavras-chave: Cartagena, hegemonia conservadora, negros, raça, política. 


\section{Presentación}

El concepto de Hegemonía conservadora es uno de los más utilizados en la historiografía colombiana para interpretar los procesos históricos que tuvieron lugar en Colombia entre 1885 y 1930. En esta categoría se agrupan los gobiernos de orientación conservadora que controlaron de manera ininterrumpida el poder político en ese país durante cuarenta y cinco años. A lo largo de esas décadas, la elite colombiana, aparte de diseñar un proyecto político de corte centralista, intentó consolidar una identidad nacional basada en los valores culturales de tradición hispánica. "Somos una nación porque somos españoles, por un idioma y una religión"1, es el lema que, según el historiador Jorge Orlando Melo, resume de mejor forma este proyecto político nacional.

El término Hegemonía conservadora, además de ser una categoría que refleja parte de los procesos que marcaron la realidad política y socio-económica de Colombia entre 1885 y 1930, se ha convertido en una importante categoría de análisis. Inicialmente, facilitó la comprensión de los esfuerzos realizados por las elites de orientación conservadora por controlar el acentuado regionalismo y las ideas liberales que habían dominado buena parte de la segunda mitad del siglo XIX ${ }^{2}$. Recientemente, en el intento de comprender el orden socio-racial que se estructuró en Colombia en el tránsito del siglo XIX al XX, varios autores lo han utilizado para reconstruir las representaciones raciales que las elites hicieron sobre los sectores afrodescendientes ${ }^{3}$ e indígenas que integraban la nación colombiana ${ }^{4}$.

El sistemático uso de la noción de Hegemonía conservadora en la historiografía colombiana no ha estado exento de revisiones que han complejizado su aplicabilidad. En los años setenta del siglo XX, el historiador Jorge Orlando Melo, analizando las dinámicas políticas del Departamento de Antioquia, alertó sobre la necesidad de ponderar el impacto de los proyectos políticos y económicos de los gobiernos conservadores a la luz de las realidades regionales y locales 5 . Dos décadas después, el también historiador Marco Palacios sugirió incluir nuevos sujetos históricos

\footnotetext{
1 Melo, Jorge Orlando. "Etnia, región y nación: el fluctuante discurso de la identidad (notas para un debate)", en Jimeno, Myrian, et al. (eds.), Identidad: Memorias del simposio identidad étnica, identidad regional, identidad nacional (Bogotá: ICANH-Colciencias-FAES, 1989), p. 37.

2 Posada Carbó, Eduardo. "Limits of Power. Elections under the Conservative Hegemony in Colombia, 1886-1930", en Hispanic American Historical Review, vol. LXXVII, núm. 2, 1997, pp. 245-279; Melo, Jorge Orlando. "La república conservadora", en Melo, Jorge Orlando (ed.), Colombia hoy (Bogotá: Banco de la República/Biblioteca Luis Ángel Arango, [1978] 1991).

3 Los censos que se hicieron a comienzos del siglo XX $(1912,1918)$ hablaban de negros y mezclados. Utilizo el término afrodescendiente como categoría de análisis para designar a las personas que abiertamente reconocían su pertenencia a la raza negra, o aquellos que, sin auto-identificarse racialmente, eran descritos como negros o mulatos.

4 Pérez, Amada. Nosotros y los otros. Las representaciones de la nación y sus habitantes, 1880-1910 (Bogotá: Universidad Javeriana, 2015); Leal, Claudia. Black Forests: The Pacific Lowlands of Colombia, 1850-1930, (tesis doctoral), University of California, 2004; Appelbaum, Nancy. Muddied Waters: Race, Region and Local History in Colombia, 1846-1948 (Durham: Duke University Press. 2003).

5 Melo, Jorge Orlando. "La república conservadora", Op Cit.
} 
Re-visitando la Hegemonía conservadora: raza y política en Cartagena (Colombia)...

(artesanos, obreros) en las narrativas que se estaban construyendo sobre la Hegemonía conservadora ${ }^{6}$.

Un estudio realizado por la historiadora Nancy Appelbaum sobre las comunidades indígenas de Río Sucio (Caldas) mostró las bondades de interpretar la Hegemonía conservadora a partir de las realidades locales y a la luz de nuevos sujetos históricos. Appelbaum, a través del análisis de la intersección entre las disputas partidistas, los procesos de colonización que tuvieron lugar en este municipio fronterizo ubicado entre Antioquia y Cauca, y los esfuerzos de sus comunidades indígenas por navegar un adverso contexto político, económico y racial, logró establecer tres elementos metodológicos claves a la hora de intentar re-pensar la Hegemonía conservadora. En primer lugar, una mirada a este periodo desde la historia local puede ubicar en el centro de la discusión los esfuerzos realizados por sectores distintos a las elites políticas e intelectuales blancas para definir su propio espacio en la nación. En segundo lugar, las transformaciones políticas que ocurrieron entre 1885 y 1930, al tiempo que establecieron límites y barreras, abrieron espacios de acción política que los sectores subordinados supieron aprovechar. Y, en tercer lugar, es posible reconstruir cómo estos sectores, en sus propios términos, cuestionaron las valoraciones raciales que de ellos hicieron los miembros de la también llamada República de los Blancos ${ }^{7}$.

Este artículo, siguiendo estos presupuestos metodológicos, pretende ofrecer una nueva aproximación a la Hegemonía conservadora a partir de la trayectoria política e intelectual construida por sectores negros y mulatos. Investigaciones previas coinciden en pintar un cuadro marcado por la escasez de liderazgos afrodescendientes en el periodo comprendido entre 1885 y 1930. En su imponente investigación sobre el liberalismo popular en la Provincia del Cauca en la segunda mitad del siglo XIX, por ejemplo, el historiador James Sanders no duda en señalar que, tras el ascenso al poder de los conservadores, "los afrocaucanos nunca volverían a jugar un papel tan destacado en la política nacional" . Las primeras décadas del siglo XX, marcadas por la consolidación de las ideas del racismo científico, también han sido tipificadas como un espacio de tiempo en el que la presencia de afrodescendientes desaparece de la esfera pública. "The rise of eugenics policies did [...] herald the further decline of Afro-Colombians in popular politics and black Colombians' status in public life", señaló recientemente el historiador Jason McGraw en su análisis sobre ciudadanía y mundo laboral en el Caribe colombiano?.

Este artículo, a partir de la realidad racial y política de Cartagena, en particular, y el Caribe colombiano, en general, pretende explorar las variaciones que en términos

\footnotetext{
${ }^{6}$ Palacios, Marco. Entre la legitimidad y la violencia. Colombia 1875-1994 (Bogotá: Ed. Vitral, 1998), p. 81.

${ }^{7}$ Appelbaum, Nancy, Op Cit., pp. 103-130.

${ }^{8}$ Sanders, James. "Ciudadanos de un pueblo libre: liberalismo popular y raza en el suroccidente de Colombia en el siglo XIX”, en Historia Crítica, núm. 38, 2009, p. 203

${ }^{9}$ McGraw, Jason. Neither Slaves nor Tyrants: Race, Labor and Citizenship in Caribbean Colombia, 18501930, (tesis doctoral), University of Chicago, 2006, p. 356.
} 
de niveles de participación política y marcos de análisis se producen en el cuadro racial excluyente que usualmente construimos en torno al dominio ejercido por las elites blancas entre 1885 y 1930. Sugiero que, en el Caribe colombiano, en el marco de la Hegemonía conservadora, emergieron dos generaciones de profesionales negros y mulatos que formaron parte la elite intelectual de esa región. Algunos de estos profesionales, junto a otros afrodescendientes que forjaron su liderazgo a partir de su participación en las guerras civiles y/o mediante su cercanía al presidente Rafael Núñez, accedieron a cargos de representación política a nivel local, regional y nacional a finales del siglo XIX. Otros, a través de la Ley de minorías políticas aprobada durante el mandato del general Rafael Reyes (1905-1909) y la posterior experiencia del republicanismo, llegaron a ser electos como concejales, diputados y congresistas. Estos profesionales y políticos negros y mulatos, a lo largo de su proceso de formación y posicionamiento, enfrentaron agravios raciales y debates por su supuesta escasez de aptitudes para acceder a los cargos de representación política e intelectual. La mayoría de estos profesionales y políticos, en ese contexto, destacaron el papel que sus antepasados habían jugado en las múltiples guerras civiles, resaltaron la idea de mérito asociada la formación profesional lograda, e hicieron uso del discurso de la ciudadanía para defender los espacios de poder que habían conquistado. Estos argumentos fueron útiles en la construcción de un lenguaje que deslegitimaba las ideas que hablaban de la supuesta inferioridad de las personas de ascendencia africana, al tiempo que permitieron cuestionar el proyecto de varios miembros de la elite blanca de legitimarse como la única y natural elite de Cartagena y Colombia en general.

\section{Generaciones pioneras}

La formación de profesionales negros y mulatos en el tránsito del siglo XIX al XX fue uno de los fenómenos sociales más significativos en el mundo socio-racial de varias ciudades latinoamericanas. En un contexto marcado por ideas que hablaban de la inferioridad de los sectores no-blancos, profesionales y políticos afrodescendientes emergieron e impactaron la realidad social de ciudades como Sao Paulo, Habana, Buenos Aires, o Montevideo ${ }^{10}$. En Colombia, uno de los países con mayor proporción de habitantes de ascendencia africana en el hemisferio occidental, las primeras generaciones de profesionales afrodescendientes surgieron en Cartagena. En este centro portuario, desde finales del siglo XVIII varios miembros de una emergente clase media de artesanos mulatos venían reclamando espacios para que a sus hijos les dispensaran su origen racial y pudieran estudiar profesiones ${ }^{11}$. Además, Cartagena, luego de consolidar su independencia de la corona española, fue una de las ciudades de la Nueva Granada que de manera temprana (1827) contó con una institución de educación superior llamada Universidad del Magdalena e Istmo. La conjugación de

\footnotetext{
${ }^{10}$ Geler, Lea. Andares negros, caminos blancos: Afroporteños, Estado y nación. Argentina a fines del siglo XIX (Rosario: Prohistoria, 2010); De La Fuente, Alejandro. A Nation for All. Race, Inequality and Politics in Twentieth Century Cuba (Chapel Hill: University of North Carolina Press, 2001); Andrews, George Reid. Blackness in the White Nation: A History of Afro-Uruguay (Chapel Hill: University of North Carolina Press, 2010) y Blacks and Whites in Sao Paulo, Brazil, 1888-1988 (Madison: University of Wisconsin Press, 1991).

${ }^{11}$ Múnera, Alfonso. El fracaso de la nación. Región, raza y clase en el Caribe colombiano, 1717-1810 (Bogotá: Banco de la República/Ancora Editores, 1998).
} 
Re-visitando la Hegemonía conservadora: raza y política en Cartagena (Colombia)...

estos factores explica la presencia de un reducido número de profesionales negros y mulatos en la citada ciudad desde la primera mitad del siglo $\mathrm{XIX}^{12}$.

Este proceso de formación de profesionales afrodescendientes continuó en la segunda mitad del siglo XIX con el proyecto educativo que los liberales adelantaron entre 1848 y 1878. Durante estas tres décadas, los gobiernos liberales, intentando consolidar su proyecto de formar ciudadanos a través de la educación, establecieron como obligación de los gobiernos federales y los distritos la financiación de la instrucción pública primaria y secundaria, al tiempo que otorgaban becas a estudiantes de bajos recursos económicos para que avanzaran en su formación profesional ${ }^{13}$.

Varios de los negros y mulatos que integraron la élite intelectual de Cartagena durante el tránsito del siglo XIX al XX iniciaron su formación profesional en el marco de este proyecto educativo liberal. En un informe realizado en 1873 por el rector de El Colegio del Estado, como entonces se llamaba la actual Universidad de Cartagena, aparecen Manuel Pájaro Herrera y los hermanos Sofronin, Teófilo y Lascario Barboza cursando sus estudios superiores en las facultades de Derecho y Medicina. Pájaro Herrera, Miranda Fuentes y Caballero Leclerc, a pesar de sus orígenes humildes, adelantaron un impresionante proceso de ascenso social a través de la educación y la política que los llevó a ocupar una posición distinguida en la aristocrática sociedad Cartagenera. Pájaro, descrito como un "moreno pardo", nació en 1851 en Getsemaní (barrio mayoritariamente habitado por sectores negros y mulatos), estudió medicina en esta institución, y luego se convirtió en profesor y decano de esa facultad Destacado y significativo fue también el papel desempeñado por este médico negro en la política al ser elegido como Concejal, diputado a la Asamblea Departamental de Bolívar, y suplente en el Senado de la República ${ }^{16}{ }^{14}$. Miranda Fuentes perteneció a una familia de profesionales negros, donde también figuraban sus hermanos Gabriel y Pedro Miranda Julio, quienes realizaron estudios de Odontología y derecho respectivamente en la Universidad de Cartagena.Al igual que sus hermanos, Eduardo Miranda también se formó en la mencionada institución, alcanzando el grado de médico cirujano y destacándose como profesor de la Los Hermanos Barboza, también habitantes del citado barrio, se inclinaron por la medicina (Lascario, Teófilo) y el derecho (Sofronin), y fueron docentes de la Universidad de Cartagena. De esta misma generación de profesionales nacidos en Getsemaní hicieron parte Eduardo Miranda Fuentes, Bartolomé Escandón y

\footnotetext{
12 Análisis sobre la Universidad de Cartagena y la formación de esos primeros profesionales negros y mulatos se encuentran en Uribe-Urán, Víctor Mario. Honorable lives: Lawyers, Family and Politics in Colombia, 1750-1850 (Pittsburgh: University of Pittsburgh Press, 2000); Múnera Cavadía, Alfonso. "Reflexiones para una historia de la Universidad de Cartagena en el siglo XIX", en Soto Arango, Diana (ed.), Historia de la Universidad en Colombia. Tomo 1. Historiografia y Fuentes (Tunja: Universidad Pedagógica y Tecnológica de Colombia, 1998), pp. 36-49.

${ }^{13}$ Al respecto: Malkum, William. Educación y politica en el Estado Soberano de Bolivar 1857-1885, (tesis de maestría), Universidad de Cartagena-Universidad Tecnológica y Pedagógica de Tunja, 2008.

${ }^{14}$ Archivo Histórico de Cartagena (AHC), "Informe del rector del Colegio del Estado", Gaceta de Bolivar, 9 de septiembre de 1881; "Alumnos que han sostenido los actos públicos en 1873", Sección Educación, Manuscritos, 23 de diciembre de 1873. Zabaleta, Horacio. Réquiem por un viejo hospital (Bogotá: Tercer Mundo, 1974), p.167.
} 
Santiago Caballero Leclerc; el primero realizó estudios de medicina y el último de odontología en la mencionada institución universitaria ${ }^{15}$.

Junto a este grupo de profesionales negros y mulatos que nacieron y crecieron en Getsemaní se destacaron otros provenientes de las provincias que estaban ligadas política y comercialmente a Cartagena. Desde el período colonial, las provincias de Cartagena, el Sinú y el Atrato estuvieron vinculadas económicamente a través de un circuito comercial que conectaba, vía mar Caribe, los ríos Sinú y Atrato. Ese circuito comercial se fortaleció a lo largo del siglo XIX y funcionó de manera fluida hasta la primera mitad del siglo XX. Miembros de la elite blanca de Cartagena invertían en minería, caucho, transporte fluvial e importación de productos en Quibdó, Lorica y Cereté, mientras comerciantes de estos tres distritos llegaban a Cartagena a vender oro y productos agrícolas ${ }^{16}$.

Este fluido circuito comercial permitió que durante la segunda mitad del siglo XIX afrodescendientes provenientes del Chocó (Camilo S. Delgado) o del puerto ribereño de Mompox (Manuel Francisco Obregón, Miguel A. Lengua) realizaran estudios profesionales y/o se vincularan como docentes a la Universidad de Cartagena. Delgado terminó siendo decano de la Facultad de Medicina, mientras Obregón y Lengua, aparte de ostentar esta posición, llegaron a ser rectores de la Universidad de Cartagena. En el ámbito de la política se desempeñó como Gobernador del Departamento de Bolívar en tres oportunidades, $(1913,1939,1941)$, Concejal, diputado, Senador, Representante a la Cámara y embajador en Alemania ${ }^{17}$. Rogelio García Hidalgo y Daniel Reyes Parra, nacidos en el distrito de San Jacinto (Bolívar), fueron otros dos profesionales pertenecientes a esta generación que hicieron estudios de derecho en la Universidad de Cartagena ${ }^{18}$. De manera que antes de finalizar el siglo XIX ya era posible identificar una primera generación de profesionales negros y mulatos que habían adelantado sus estudios universitarios en el marco de los gobiernos liberales.

Los miembros de la segunda generación iniciaron sus estudios en las primeras décadas de la Hegemonía conservadora. La gran mayoría eran hijos de artesanos que habían logrado cierta movilidad social a finales del siglo XIX. Los hermanos Daniel, Raúl,

\footnotetext{
${ }^{15} \mathrm{AHC}$, "Exámenes preparatorios al grado de doctor en médicina y cirujía, de los alumnos de $5^{\circ}$ año de la Universidad" y "Santiago Caballero Leclerc", El Porvenir, 8 de enero de 1899. En un artículo publicado en el periódico El Penitente, Eduardo Miranda señala que él con sus orígenes oscuros también puede contribuir al desarrollo de la nación. AHC, "ME DEFIENDO", El Penitente, 3 de julio de 1910.

${ }^{16}$ Una reciente reconstrucción sobre ese circuito comercial entre Cartagena y las provincias del Sinú y Atrato la hace Rhenals Doria, Ana Milena. "Tejiendo la red: circuitos comerciales, inmigrantes sirio-libaneses y empresarios nacionales en el Caribe colombiano y el Atrato (1880-1930)", en Historia y Espacio, núm. 37, 2011, pp. 189-212.

${ }^{17}$ Flórez Bolívar, Francisco Javier. Beyond the White Republic: Afro-descendant Elites, Race and Citizenship in Cartagena (Colombia) 1903-1945, (tesis de maestría), University of Pittsburgh, 2011. Obregón, originario del puerto ribereño de Mompox, este médico mulato graduado en el Colegio Mayor del Rosario de Bogotá y con especializaciones en Francia y Alemania, fue profesor y rector de la Universidad de Cartagen

${ }^{18}$ Sobre la trayectoria de estas figuras políticas: Pereira Caro, José Joaquín y Manrique Fernández, Miguel. Fragmentos históricos de San Jacinto (Bolívar, Cartagena: Alpha editores, 2015).
} 
Eusebio y Francisco de Paula Vargas en Dentro de los casos más significativos de esa primera mitad del siglo XX podemos destacar el de los hermanos Vargas Vélez. Los hermanos Daniel, Eusebio y Raúl Vargas, hijos de un artesano negro chocoano, también se formaron como médicos en la Universidad de Cartagen fueron unos de los miembros más destacados de esta segunda generación. Hijos de un artesano negro del Chocó, que también comerciaba oro entre Quibdó y Cartagena, nacieron en Getsemaní e ingresaron a la Universidad de Cartagena. Los tres primeros estudiaron medicina, mientras el último se graduó como abogado ${ }^{19}$. Algunos de los hijos de los miembros de la primera generación también hicieron parte de esta segunda generación de profesionales. Gracias al ascenso profesional de sus padres, varios de ellos adelantaron sus estudios en Cartagena y Bogotá, o viajaron al exterior a realizar especializaciones, logrando un importante grado de distinción social e intelectual en Cartagena ${ }^{20}$.

Esta segunda generación también se nutrió de afrodescendientes que provenían de distritos que hacían parte de la provincia de Cartagena. Demetrio Morillo y José de los Santos Cabrera, oriundos de Barú (distrito habitado por descendientes de esclavos y negros libres), son dos de los casos que ejemplifican lo anotado. Ambos ingresaron a la Facultad de Derecho de la Universidad de Cartagena, y terminaron siendo docentes de la citada facultad ${ }^{21}$. Estudiantes negros y mulatos procedentes de las áreas agrícolas y ganaderas de los actuales departamentos de Córdoba (Moisés Pianeta) y Bolívar (Prospero Villanueva) también ingresaron a estudiar medicina y se integraron a la segunda generación de profesionales afrodescendientes de Cartagena. Con el tiempo, tanto Villanueva como Pianeta terminaron siendo docentes de esta facultad, y el último llegó a ser su decano ${ }^{22}$.

Un seguimiento a la trayectoria de estas dos generaciones de profesionales permitió reconstruir un total de ochenta perfiles con gran figuración en el escenario académico de Cartagena entre 1885 y 1930 . Este número de negros y mulatos con formación profesional era reducido para una ciudad donde, según el censo de 1912, más del 80\%

\footnotetext{
${ }^{19}$ Sobre los orígenes raciales de los hermanos Vargas Vélez: Valdelamar, Juan y Gutiérrez, Juan. Getsemaní. Oralidad en atrios y pretiles (Cartagena: Litografías del Mar, 2005), pp. 126-133 y Angulo, Álvaro. Aspectos sociales y politicos de Cartagena de Indias. Siglos XVI y XIX (Barranquilla: Antillas, 2001), p. 165.

${ }^{20}$ Francisco Obregón Jarava, hijo de Manuel F. Obregón, estudió medicina en Bogotá y Francia; Luis C. Delgado, hijo de Camilo S. Delgado, se hizo médico en Philadelphia University; Pedro Herrera, hijo del artesano Estuardo Herrera, adelantó su especialización en radiología en la Universidad de Chicago. Francisco Obregón fue decano de la Facultad de Medicina y rector de la Universidad de Cartagena; Pedro Herrera fue concejal y alcalde de Cartagena, y Luis Carlos Delgado también fue profesor de esta institución. Sobre la trayectoria de estos profesionales negros: Maza, Edwin. Facultad de Medicina de la Universidad de Cartagena. Su historia (Cartagena: Universidad de Cartagena, 1998), pp. 147-149; Flórez Bolívar, Francisco Javier. Beyond the White Republic: Afro-descendant Elites, Race and Citizenship in Cartagena (Colombia) 1903-1945, (tesis de maestría), University of Pittsburgh, 2011.

${ }^{21}$ Biblioteca Nacional de Colombia (BNC), "José Santos Cabrera” y "Demetrio Morillo", El Mundo, 13 de junio de 1935.

${ }^{22}$ Maza, Edwin, Op Cit., pp. 147-152.
} 
de la población masculina (14.788) eran de origen afrodescendiente ${ }^{23}$. Sin embargo, es necesario tener en cuenta el escaso número de profesionales que caracterizó la vida intelectual de Cartagena hasta las cuatro primeras décadas del siglo XX. Algunas de las estadísticas existentes sobre el número de estudiantes registrados en las facultades de medicina y derecho de la Universidad de Cartagena así lo reflejan. Por ejemplo, en 1881, un informe del rector de esta institución señalaba que en los cinco cursos de la primera facultad sólo estaban matriculados veintidós estudiantes, mientras que la última escasamente contaba con quince alumnos ${ }^{24}$. Este bajo número de estudiantes se vio reflejado en el pequeño grupo de profesionales que aparece registrado en los censos de la primera mitad del siglo XX. De acuerdo con el censo de 1912, cuando la población de Cartagena era de 36.632 habitantes, solo 114 personas ejercían profesiones liberales. Veintiséis años después, cuando el número de habitantes de la ciudad había llegado a 72.767, los profesionales liberales habían ascendido a 443, de los cuales 347 eran colombianos y 96 eran extranjeros ${ }^{25}$.

La importancia del número de profesionales negros y mulatos en Cartagena durante este periodo toma más fuerza cuando precisamos lo que según los censos de comienzos del siglo XX definían como profesiones liberales. El censo de 1912, por ejemplo, incluía treinta y seis oficios que iban desde porteros, impresores, tipógrafos, pasando por agrimensores, dactilógrafos, taquígrafos, hasta llegar a profesionales en odontología, derecho, medicina, veterinaria y odontología. En 1938, año en que se realizó el primer censo moderno de Colombia, algunos columnistas hicieron alusión a las inconsistencias que enfrentaron los censos de 1912, 1918 y 1928 para precisar cuáles oficios debían catalogarse como profesiones liberales. "En la declaración de la profesión u oficio, se han visto respuestas como estas: "hijo de cocinera"; un padre sentimental dijo de su hijita "encanto del hogar" [...] sin contar con yerbateros, albañiles y tinterillos que se gradúan ellos mismos de médicos, ingenieros y abogados, concluyó un columnista"26.

La ambigüedad de que estaba recubierta la categoría profesiones liberales en los censos no permite establecer con exactitud el número de abogados y médicos con que contaba Cartagena, profesiones donde los sectores negros y mulatos tenían una gran presencia. Y la ausencia de micro-datos para cruzar las variables ocupacionales con las de raza imposibilita precisar cuántos del grupo total de profesionales registrados en los censos eran de origen afrodescendiente y cuántos no. De lo que no hay duda es del grado de influencia que estos profesionales, provenientes de los barrios pobres de Cartagena y de las provincias ligadas a su vida intelectual, comercial y portuaria, obtuvieron en el tránsito del siglo XIX al XX. Manuel F. Obregón, Lascario Barboza, Manuel Pájaro y Bartolomé Escandón, por ejemplo, hicieron parte del grupo de médicos que crearon la Sociedad de Medicina y Ciencias Naturales de Bolívar en al año de 1888, y terminaron presidiéndola en varias oportunidades. Obregón y Pájaro,

\footnotetext{
${ }^{23}$ Censo general de la República de Colombia, Bogotá: Imprenta Nacional, 1912.

${ }^{24}$ Biblioteca Bartolomé Calvo (BBC), Gaceta de Bolivar, 9 de septiembre de 1881.

${ }^{25}$ Censo general de la República de Colombia, Bogotá: Imprenta Nacional, 1912.

${ }^{26}$ AHC, "El censo", Anales del Concejo, 19 de febrero de 1938.
} 
junto a Camilo S. Delgado, también participaron en la fundación de la Academia de Historia de Cartagena en $1911^{27}$.

Observadores de la época fijaron su atención en la interesante trayectoria profesional alcanzada por algunos afrodescendientes de Cartagena, argumentando que estos sectores -y no los miembros de la elite blanca- lideraban la vanguardia intelectual de la ciudad. El periodista Julián Devis Echandía, hablando de las dinámicas sociales de Cartagena durante la primera mitad del siglo XX, dejó constancia de esta interesante realidad intelectual en su libro La ciudad vencida. Luego de sugerir que buena parte de los miembros de las clases aristocráticas habían aportado poco al mundo intelectual de la ciudad, pues en su mayoría eran comerciantes dedicados a la usura, este periodista expresó lo siguiente:

\begin{abstract}
No así las clases negras y mulatas. Comprendiendo que tenían en sus manos una misión histórica que cumplir, los jóvenes de las clases medias, negros, mulatos, indios, mestizos y blancos, se concretaron al estudio, invadieron las universidades, los colegios, se apartaron de los vicios y han quemado durante un siglo sus pestañas con el fuego de la esperma que alumbra el libro: Manuel F. Obregón, Francisco de P. Vargas Vélez, José Santos Cabrera, Demetrio Morillo, Macario Paz, Clodomiro Herrera Meñaca, Wilfrido Castro, Daniel y Eusebio Vargas, José Caballero Leclerc, Luis Carlos González, José Morillo, Carlos Manuel Hernández, Raúl Bernett y Córdoba, cien más ocupan la vanguardia de la juventud pujante de Cartagena ${ }^{28}$.
\end{abstract}

\title{
De la escala nacional al lente local
}

¿Qué pasa cuando ubicamos estas generaciones de profesionales afrodescendientes en las dinámicas políticas que tuvieron lugar a nivel local y regional durante los años de la Hegemonía conservadora? ¿Experimenta alguna transformación el cuadro de pleno dominio de las elites blancas conservadoras y total exclusión de los sectores negros y mulatos? Hace algunos años, el historiador Sergio Paolo Solano, matizando el peso que habían tenido los mecanismos de control social ejercido por los gobiernos conservadores sobre los sectores populares, ofreció algunos elementos de análisis útiles para resolver estos interrogantes. Solano sugirió que el cuadro de pleno control logrado por los mismos obedece a la inevitable comparación que se hace entre el alto grado de movilización y poder político adquirido por los sectores populares durante el dominio liberal y el que alcanzaron en las décadas finales del siglo XIX ${ }^{29}$.

\footnotetext{
${ }^{27}$ Flórez Bolívar, Francisco Javier. "Iluminados por la educación: los ilustrados afro-descendientes del Caribe colombiano a comienzos del siglo XX", en Cuadernos de Literatura del Caribe e Hispanoamérica, núm. 9, 2010, pp. 35-58; Zabaleta, Horacio, Op Cit. p. 190.

${ }^{28}$ Devis Echandía, Julián. La ciudad vencida. La Cartagena de ayer, la Cartagena de hoy (Bucaramanga: Gómez y Páez, 1937), p. 167.

${ }^{29}$ Solano, Sergio Paolo. "Política, religión e intelectuales en el Caribe Colombiano durante la Regeneración (1886-1899)", en Historia Caribe, núm. 4, 1999, pp. 43-60.
} 
En la costa Caribe colombiana, donde varios líderes negros y mulatos accedieran a los más altos cargos de representación política que se podían lograr durante el régimen federal ${ }^{30}$, esa comparación hace suponer de manera a priori que los liderazgos afrodescendientes disminuyen dramáticamente en el tránsito del liberalismo radical a la Hegemonía conservadora. Sin embargo, es necesario matizar -a partir de las dinámicas locales y regionales- el cuadro de nula movilización política y de plena exclusión afrodescendiente que supuestamente caracterizó este periodo, al tiempo que es pertinente determinar si los niveles de exclusión social y política de los profesionales y políticos negros y mulatos experimentaron alguna variación en el marco de las transformaciones socio-políticas que tuvieron lugar entre 1880 y 1930.

El carácter relacional de las identidades, ampliamente mencionado en la historiografía reciente que ha abordado el tema de las relaciones raciales, también puede contribuir a problematizar la visión de exclusión total que se ha construido sobre la Hegemonía conservadora. Recientes análisis han sugerido que las identidades raciales interactúan con otras formas de identidad. En otros términos, los grupos sociales, en su diaria interacción, construyen un conjunto de relaciones económicas, sociales y políticas que no se pueden visualizar solo a partir de un plano racial ${ }^{31}$. Un ejemplo que sirve para ilustrar la relevancia de tener en cuenta el carácter relacional de las identidades en el marco de las dinámicas de la Hegemonía conservadora tiene que ver con la posición asumida por Rafael Núñez frente al ascenso político de varios políticos de origen afrodescendiente. Luis 'el negro' Robles, siendo presidente del Estado Soberano del Magdalena (1877-1879), enfrentó una férrea oposición de parte de Núñez que finalmente derivó en la separación de Robles del cargo y su posterior apresamiento ${ }^{32}$. Amparándonos únicamente en el plano racial, podríamos argumentar que las ideas sobre la supuesta inferioridad racial de los sectores negros que manejaban varios miembros de la élite política e intelectual de manera mecánica explicarían la actitud beligerante de Núñez contra Robles. Este marco interpretativo, sin embargo, deja poco espacio para explicar diversas instancias en las que este político conservador dio muestras que su pensamiento racial era mucho más complejo de lo que usualmente asumimos. Al tiempo que ejerció una abierta oposición a la administración de Robles, Rafael Núñez tomó la decisión de nombrar al abogado negro Daniel J. Reyes como gobernador de la Provincia del Carmen de Bolívar (1878-1880), y durante su tercer período presidencial (1887-1888) lo designó como su secretario privado ${ }^{33}$.

\footnotetext{
${ }^{30}$ Juan José Nieto y Manuel Ezequiel Corrales, ambos de origen afrodescendiente, presidieron el Estado Soberano de Bolívar, y Luis "el negro" Robles fue presidente del Estado Soberano del Magdalena.

${ }^{31}$ Grossberg, Lawrence. "Identidad y estudios culturales", en Hall, Stuart y Du Gay, Paul (eds.), Cuestiones de identidad (Buenos Aires: Amorroru editores, 2003), p. 152; Wade, Peter. "Identidad", en Serge, Margarita; Suaza, María Cristina y Pineda, Roberto (eds.), Palabras para desarmar (Bogotá: ICANH, 2002), p. 255.

${ }^{32}$ McGraw, Jason. The Work of Recognition: Caribbean Colombia and the Postemancipation Struggle for Citizenship (Chapel Hill: University of North Carolina Press, 2014), pp. 140 y 155.

${ }^{33}$ Sobre la trayectoria del político de Daniel J. Reyes: José Pereira Caro y Miguel Manrique Fernández. Fragmentos históricos de San Jacinto, Bolívar (Cartagena: Alpha editores, 2015).
} 
Mucho más revelador de la complejidad del pensamiento racial de Rafael Núñez fue la posición asumida frente a las resistencias que elites intelectuales andinas expresaron ante el nombramiento que hizo del abogado afrodescendiente Manuel Ezequiel Corrales como rector del Colegio Mayor del Rosario en 1880. Núñez, tras esa designación, tuvo que confrontar los cuestionamientos raciales que varios miembros de la elite bogotana hicieron en contra de Corrales. En respuesta, Núñez les recordó a sus opositores las trágicas consecuencias que los odios raciales habían causado en los Estados Unidos: "Se ha olvidado la historia trágica de los plantadores del sur de los Estados Unidos. ¿Qué queda hoy a esos hombres infatuados, de su dominación ominosa de otro tiempo? Ellos también sembraron imprudentemente la cizaña en el suelo americano". Y luego concluyó: "La raza proscrita por ellos ha ascendido a las alturas de la ciudadanía; y los cuatro mil millones de pesos que representaban el valor de los esclavos y la fortuna de los soberbios, quedaron reducidos a cero por un decreto inmortal del presidente Lincoln $[\ldots]^{\prime 34}$.

La férrea oposición de Núñez a la administración de Luis ‘el negro’ Robles, más que corresponderse con unas motivaciones raciales, parece encontrar explicación en la negativa de los liberales radicales del Magdalena, entre esos Robles, de apoyar su primera candidatura presidencial en el año de 1875. Durante esas elecciones, el mismo Núñez tuvo que contrarrestar los insultos raciales que miembros de la facción radical del liberalismo - encabezados por Aquileo Parra- hicieron en contra del significativo número de sectores negros y mulatos de la costa Caribe que apoyaron su candidatura ${ }^{35}$. A la hora de analizar las dinámicas de inclusión/exclusión de los sectores afrodescendientes en el marco de la Hegemonía conservadora, entonces, es necesario tener en cuenta que los vínculos personales, las ideologías partidistas y la pertenencia regional también fueron factores determinantes para acceder a los cargos de representación política.

Desde la esfera relacional de las identidades también podemos entender el rol político que jugaron algunos negros y mulatos que eran miembros destacados del Partido Conservador. Como lo sugirió el historiador James Sanders, la asociación entre afrodescendiente y militancia liberal, aunque cierta y mayoritaria, no debe ocultar ni minimizar la presencia de políticos de ese origen racial al interior del Partido Conservador. Durante el dominio conservador en Cartagena, por ejemplo, el médico negro Manuel Pájaro Herrera fue miembro de la Asamblea Departamental (1884) y presidente del Concejo Municipal de Cartagena desde 1888 hasta 1891, al tiempo que el también médico mulato Camilo S. Delgado fue presidente de esta última entidad política en $1895^{36}$.

Identificar los espacios de acción política que se abrieron a nivel local y regional para los políticos negros y mulatos en el marco de la Hegemonía conservadora

\footnotetext{
${ }^{34}$ Núñez, Rafael. La reforma política (Medellín: editorial Lealon, 1994), p. 59.

${ }^{35}$ McGraw, Jason, Op Cit., p. 253.

${ }^{36}$ BBC, Registro de Bolivar Cartagena, 7 de febrero de 1895. También: Otero, Samuel. Cien costeños meritorios, tomo I (Cartagena: Imprenta Departamental, 1918), pp. 216-217.
} 
también puede ayudarnos a matizar los niveles de movilización y liderazgo logrados por los sectores afrodescendientes entre 1885 y 1930. La guerra civil de 1885, dado el papel destacado que tuvieron en la misma algunos militares de ese origen racial, merece especial atención. Iniciada por liberales radicales del Estado Soberano de Santander, inconformes con las políticas centralistas de Rafael Núñez, esa guerra se fue extendiendo por distintos centros urbanos liberales del país. En el Caribe colombiano, el puerto de Colón (actual Panamá) fue uno de los escenarios donde sectores negros y mulatos vinculados al Partido Liberal participaron activamente en el mencionado conflicto. En ese centro portuario, para entonces territorio colombiano, las acciones lideradas por Pedro Prestán permiten destacar liderazgos que siguieron siendo centrales a finales del siglo XIX. En marzo de 1885, Prestán, un mulato nacido en Cartagena, encabezó un movimiento revolucionario al que también se vincularon inmigrantes afro-antillanos que le permitió convertirse por un corto tiempo en jefe civil y militar de la ciudad de Colón ${ }^{37}$.

Igual atención amerita la Guerra de los Mil Días (1899-1902), el punto de inflexión más significativo para analizar las transformaciones y cambios políticos que se produjeron en las tres últimas décadas de la Hegemonía conservadora. Diversos estudios han sugerido que este conflicto, al tiempo que cerró espacios, abrió posibilidades de movilidad política para los sectores negros y mulatos. Por un lado, el inicio de esta prolongada guerra civil se tradujo en la separación efectiva de los liberales de los cargos públicos que ocupaban en los gobiernos conservadores. En efecto, el médico liberal Manuel Francisco Obregón, quien había sido nombrado rector de la Universidad de Cartagena en 1899, fue forzado a abandonar su cargo y exiliarse en Costa Rica debido a las violentas confrontaciones que surgieron con el inicio de la guerra de los Mil Días ${ }^{38}$. Y por otro, la participación de sectores afrodescendientes en esta conflagración incidió en la posterior movilidad social y política de algunos militares negros y mulatos. La experiencia de Joaquín Mercado Robles es, tal vez, la que mejor refleja ese proceso. Mercado Robles, quien llegó a ser Comandante General del ejército liberal del Departamento de Bolívar, tras su participación en esta guerra, se convirtió en una figura destacada del liberalismo, siendo electo posteriormente como diputado a la Asamblea Departamental de Bolívar ${ }^{39}$.

La importancia de este nuevo conflicto político para los afrodescendientes que jugaron un papel central en la vida política de Cartagena y el Caribe colombiano durante la primera mitad del siglo XX también radicó en los espacios que se abrieron con la redefinición de las relaciones políticas entre conservadores y liberales. En 1904, un año después de la separación de Panamá, el general conservador Rafael Reyes asumió la presidencia de Colombia bajo la promesa de la unificación nacional. A través del nombramiento de varios políticos liberales en su administración, Reyes

${ }^{37}$ Coniff, Michael. Black Labor on a White Canal. Panama, 1904-1981 (Pittsburgh: University of Pittsburgh, 1985), pp. 135 y 220.

${ }^{38}$ AHC, "Manuel Francisco Obregón”, El Republicano, 28 de diciembre de 1912.

39 Álvarez Jiménez, Jairo. "Las caras diversas de las guerras civiles en el Bolívar Grande (Colombia, siglo XIX)", en Anuario de Historia Regional y de las Fronteras, vol. XIX, núm. 2, julio-diciembre 2014, pp. 529-553. 
intentó proyectar esa imagen de reconciliación partidista. Sin embargo, debido a la vehemente oposición de una de las facciones del partido conservador, el gobierno de Reyes asumió posiciones dictatoriales. En 1905, clausuró el Congreso, declaró el estado de sitio, y convocó una asamblea constitucional integrada por representantes de los partidos conservador y liberal. Las aspiraciones dictatoriales de Reyes llegaron a su fin en el año de 1909, cuando una coalición de liberales y miembros pertenecientes a la facción Histórica del conservatismo presionaron y exigieron su renuncia. Un año más tarde, bajo las banderas de un movimiento político llamado republicanismo, algunos miembros de los partidos Liberal y Conservador se unieron para avanzar en la modernización económica y política del país ${ }^{40}$.

¿Qué espacios se abrieron a nivel local para los sectores afrodescendientes en el marco de estas transformaciones políticas? El derecho de representación de las minorías políticas en las elecciones a corporaciones públicas reglamentado por la asamblea constitucional convocada por el general Reyes fue uno de esos primeros espacios. La idea era que el partido político que alcanzara la segunda mayor votación tuviera una representación proporcional en los cuerpos colegiados. Esta condición de minoría usualmente era ocupada por el Partido Liberal. En ciudades como Cartagena, donde la mayoría de los profesionales y políticos negros y mulatos integraron y ocuparon cargos directivos en el Partido Liberal, la Ley de minorías políticas fue decisiva para que varios de ellos salieran electos como concejales o diputados de la Asamblea departamental de Bolívar. La conformación del republicanismo también terminó incidiendo en el posicionamiento de algunos políticos afrodescendientes. Pese a que algunos de ellos, como el médico liberal Eduardo Miranda Fuentes, rechazaron cualquier alianza con sectores conservadores; otros terminaron vinculándose al republicanismo. La familia compuesta por los hermanos Santiago, Jesús, Juan y Miguel Caballero Leclerc, por ejemplo, creó el periódico La Verdad (1912), órgano defensor de la causa republicana en Cartagena. Ese declarado espíritu republicano se tradujo en la presencia de algunos integrantes de esta familia en el mandato del gobernador conservador José Antonio Gómez Recuero, quien nombró al médico Santiago Caballero Leclerc como Inspector Provincial de Instrucción Pública en $1912^{41}$. Manuel F. Obregón y Miguel Lengua, otros dos liberales que terminaron siendo miembros destacados del republicanismo en Cartagena, también ocuparon cargos públicos de importancia durante este periodo. Obregón, participando en las listas del republicanismo, fue electo concejal y diputado a la Asamblea Departamental de Bolívar en 1910 y 1911 respectivamente. En 1912, el gobernador Gómez Recuero lo nombró como secretario de Gobierno Departamental, y luego fue designado gobernador encargado de Bolívar entre los meses de agosto y noviembre de $1913^{42}$. Lengua, por su parte, fue elegido como diputado de la Asamblea Departamental de Bolívar en el año de $1911^{43}$.

\footnotetext{
${ }^{40}$ Posada Carbó, Eduardo. "Limits of Power. Elections under the Conservative Hegemony in Colombia, 1886-1930”, Op Cit., p. 253.

${ }^{41}$ AHC, "Una destitución”, La Verdad, 27 de marzo de 1913.

${ }^{42}$ AHC, "Concejales municipales", El Liberal, 30 de abril de 1910; "El escrutinio del municipio de Cartagena", El Imparcial, 6 de junio de 1911; "Nota editorial”, El Verbo, 29 de agosto de 1913.

${ }^{43}$ AHC, "Escrutinio general", El Liberal, 26 de febrero de 1911.
} 
El dinamismo organizativo que recobran las organizaciones artesanales y la irrupción de las clases obreras a comienzos del siglo XX también incidió en el posicionamiento político de líderes negros y mulatos. Durante las tres primeras décadas del siglo XX, como lo demostró recientemente Jason McGraw, trabajadores de ese origen racial -a través de movilizaciones y participación en la vida política local y regional-incidieron en la expansión y consecución de sus derechos laborales ${ }^{44}$. La figuración que logran los miembros de la segunda generación a partir de 1920 la alcanzan, en parte, a través de las conexiones que tejen con artesanos y obreros. Para lograr esas conexiones, las figuras afrodescendientes que hacían parte de los partidos liberal y conservador organizaban listas conjuntas de candidatos a cargos de representación local y/o se vinculaban a las juntas directivas de las organizaciones obreras ${ }^{45}$. Esta interacción política con los sectores artesanales y obreros les permitió a varios líderes de la segunda generación de afrodescendientes ser elegidos como concejales y diputados departamentales ${ }^{46}$. En 1930, cuando cae la Hegemonía conservadora, el poder-local y regional- alcanzado por políticos negros y mulatos provenientes de Cartagena y la costa Caribe era notable. Algunos de estos líderes políticos, incluso, extendieron su poder político a las esferas nacionales.

\section{Negros y mulatos y su ascenso a la Atenas suramericana}

La consecución de estos importantes espacios de poder a nivel local y regional fue clave para que varios políticos y profesionales negros y mulatos ocuparan cargos de representación a nivel nacional durante la Hegemonía conservadora. Bogotá no solo fue el centro desde donde se impulsaron imágenes raciales que luego se dispersaron por el resto del territorio nacional. También, fue el escenario donde algunos profesionales y políticos de distintas regiones llegaron a desempeñar cargos intelectuales y políticos, entre ellos algunos negros y mulatos provenientes de la costa Caribe colombiana. La cercanía con Rafael Núñez fue útil para que algunos políticos adquirieran una significativa figuración nacional. Manuel Ezequiel Corrales, aparte de su desempeño como rector del Colegio Mayor del Rosario, fue senador y magistrado de la Corte Suprema de Justicia ${ }^{47}$. Daniel J. Reyes Parra, en 1888, luego de renunciar a su cargo como secretario privado de Núñez, fue representante a la cámara y senador en varias

\footnotetext{
${ }^{44}$ McGraw, Jason, Op Cit., p. 220.

${ }^{45}$ En 1919, Demetrio Morillo y José Caballero Leclerc, junto a los artesanos Estuardo Herrera y Pedro Malabet, integraron la lista de candidatos al concejo por el Partido Liberal. Cinco años después, Francisco de P. Vargas fue electo tesorero del Directorio Obrero Departamental, una organización que agrupaba a los artesanos y obreros del Departamento de Bolívar. AHC. "Lista del liberalismo al concejo", El Liberal, 4 de octubre de 1919; "Del obrerismo", El Debate, 30 de mayo de 1925.

${ }^{46}$ Demetrio Morillo (1920-1921, 1922-1924), Francisco de P. Vargas (1922-1924), José Caballero Leclerc (1920-1921), Manuel F. Obregón (1928-1929) y Miguel Lengua (1929-1930) fueron concejales. Francisco de Paula Vargas y Demetrio Morillo fueron electos diputados (1929-1929). "Los ediles de Cartagena", La Época, junio 12 de 1920 "Barrio obrero", El Humanitario, 12 de abril de 1923; "Cuestiones municipales", Diario de la Costa, 10 de marzo de 1923; "El representante Vargas Vélez hace unas declaraciones", El Mercurio, 11 de julio de 1929.

${ }^{47}$ Corrales, Manuel Ezequiel. Efemérides y anales del Estado Soberano de Bolívar (Cartagena: Gobernación de Bolívar/Instituto Internacional de Estudios del Caribe/Carlos Valencia editores, 1999).
} 
oportunidades $^{48}$. Otros políticos, que forjaron su liderazgo dentro de las filas del liberalismo, también lograron acceder a ciertos espacios de representación durante estos años de dominio conservador. El caso más significativo fue el de Luis "el negro" Robles, quien ocupó una curul en el Congreso de la República entre 1892 y 1894, y posteriormente, fue nombrado miembro de la dirección nacional del Partido Liberal ${ }^{49}$.

La presencia en la vida política nacional de negros y mulatos provenientes de la costa Caribe toma mayor fuerza en las tres primeras décadas del siglo XX. Los líderes políticos que crecieron bajo la sombra de Núñez siguieron accediendo a cargos de representatividad política nacional. Daniel J. Reyes fue nombrado gobernador del Distrito Capital de Bogotá (1909-1910) y luego, ocupó el cargo de secretario de la cámara de representantes (1913), mientras que el médico negro Manuel Pájaro Herrera fue electo congresista ${ }^{50}$. Al igual que ocurrió en los ámbitos locales y regionales, la participación en la guerra de los Mil Días, la reconfiguración de las relaciones políticas entre liberales y conservadores, la Ley de minorías políticas y la experiencia del republicanismo fueron dinámicas claves para que varios afrodescendientes pertenecientes al partido Liberal- terminaran figurando en cargos de representación nacional.

Las trayectorias de Rogelio García Hidalgo, Miguel A. Lengua y Manuel Francisco Obregón sirven para sustentar lo anotado. García Hidalgo, general de la República durante la guerra de los Mil Días, fue elegido representante a la cámara por la circunscripción electoral de Barranquilla (1909-1910). A través de la ley de minorías políticas, Obregón y Lengua también llegaron a esta corporación y al senado en distintas oportunidades (1911-1913, 1917-1919, 1919-1923, 1921-1923, 1929$931)^{51}$. El grado de influencia alcanzado por algunos de estos afrodescendientes se vio reflejado también en las posiciones de liderazgos que lograron en los espacios de representación política que empezaron a ocupar. Por ejemplo, Rogelio García Hidalgo fue vicepresidente de la Asamblea Nacional Constituyente y Legislativa que se reunió en 1907, mientras que Manuel Francisco Obregón fue presidente de la Cámara de Representantes en $1922^{52}$. La figuración más significativa la logró el político conservador Daniel Reyes Parra, quien fue nombrado Ministro del Tesoro durante el mandato de José Vicente Concha (1914-1918) ${ }^{53}$.

\footnotetext{
${ }^{48}$ Archivo del Congreso (AC), Anales de la Cámara de Representantes, 29 de julio de 1896 y 10 de agosto de 1898.

${ }^{49}$ AC, Anales de la Cámara de Representantes, 3 de agosto de 1892.

${ }^{50}$ Otero, Samuel, Op Cit., p. 216.

${ }^{51}$ AC, Anales de la Cámara de Representantes, 1 de agosto de 1911, 1 de agosto de 1917, 26 de julio de 1919, 30 de julio de 1921 y 22 de julio de 1929.

${ }^{52}$ AHC, "Manuel Francisco Obregón", Gaceta Departamental de Bolivar, Cartagena, 20 de diciembre de 1922.

${ }^{53}$ AHC, Diario Oficial, 16 de septiembre de 1914.
} 


\section{En sus propios términos}

La historiografía colombiana ha avanzado en las representaciones raciales que las elites blancas construyeron sobre los sectores negros e indígenas en el marco de la Hegemonía conservadora. Esta perspectiva ha sido sumamente importante para dilucidar los usos y las variaciones que los discursos raciales han experimentado en Colombia $^{54}$. Junto a este plano de análisis, clave a la hora de entender el régimen de representación racial que se estructuró entre 1885 y 1930, también es necesario que cada vez más nos cuestionemos por los términos a través de los cuales los representados reclamaron su propio lugar en el marco de la Hegemonía conservadora.

El referenciado trabajo de Nancy Appelbaum avanzó en la reconstrucción de las acciones y los términos utilizados por las comunidades indígenas de Río Sucio. Esta autora demostró que, a través de sus alianzas locales y de su participación en las guerras civiles, los indígenas adquirieron un grado de negociación política que fue decisivo para determinar qué terrenos colectivos eran divididos y cuáles no. Estas comunidades, frente a las ideologías de blanqueamiento propuestas desde el gobierno nacional, reafirmaron su identidad indígena, y a partir de esta reclamaron el derecho a mantener los terrenos comunales que la Ley de resguardos (Ley 89 de 1890) consideró legales ${ }^{55}$.

Hallazgos similares se pueden reconstruir cuando analizamos los esfuerzos realizados por estos sectores afrodescendientes para acceder a los espacios de poder político e intelectual. Colombia distaba de ser un paraíso racial en el que estos profesionales y políticos negros y mulatos accedían sin restricciones raciales a los espacios de representación. Los profesionales y políticos afrodescendientes, por su formación y liderazgo, competían por los cargos que se suponían eran reservados de manera natural para la elite blanca. Esta circunstancia, como lo sugirió recientemente la historiadora Paulina Alberto al analizar la trayectoria política de intelectuales afrobrasileros durante el siglo XX, expuso a los profesionales y políticos negros y mulatos a mayores niveles de discriminación e insultos racistas. De allí que, según la mismo Alberto, el seguimiento al posicionamiento de intelectuales de ese origen racial sea una excelente ventana para reconstruir los límites y alcances del discurso de la ciudadanía en varios países latinoamericanos ${ }^{56}$.

\footnotetext{
${ }^{54}$ Entre los trabajos recientes que hacen uso de esta perspectiva se destacan Martínez Pinzón, Felipe. Una Cultura de invernadero: Trópico y civilización en Colombia (1808-1928) (Madrid y Frankfurt: Iberoamericana-Vervuert, 2016); Pérez, Amada, Op Cit.; Múnera Cavadía, Alfonso. "Pensando las identidades: de Caldas a Caro", en Múnera Cavadía, Alfonso. Tiempos difíciles. La república del XIX: una ciudadanía incompleta (Bogotá: Pluma de Mompox, 2011), pp. 31-39; Leal, Claudia, Op Cit.

${ }^{55}$ Appelbaum, Nancy, Op Cit., pp. 128-132.

${ }^{56}$ Alberto, Paulina. Terms of Inclusión. Black Intellectual in Twentieth-Century Brazil (Chapel Hill: University of North Carolina Press, 2011), p. 21.
} 
Re-visitando la Hegemonía conservadora: raza y política en Cartagena (Colombia)...

Esos límites y alcances -en Colombia- se pueden reconstruir a partir de las barreras raciales que tuvieron que confrontar varios de los profesionales y políticos afrodescendiente de Cartagena y del Caribe colombiano cuando ocuparon cargos intelectuales y políticos a nivel local y nacional. A finales del siglo XIX, el evento que mejor ilustra la demarcación de las fronteras raciales fue el ya comentado nombramiento de Manuel Ezequiel Corrales como rector del Colegio Mayor del Rosario de Bogotá en 1880. Según lo establecido por Rafael Núñez en el artículo "El Cisma", publicado en su texto La Reforma Política, el nombramiento de Corrales generó ciertas resistencias al interior de las élites intelectuales del mundo andino. El origen racial del abogado cartagenero se estaba utilizando para impedir que asumiera la rectoría de un centro educativo que durante el periodo colonial había exigido certificados de pureza de sangre a sus alumnos como requisito de ingreso ${ }^{57}$. Tres años más tarde, los agravios raciales recayeron sobre Luis "el negro" Robles, quién para la época era Representante a la Cámara. Esta vez, en medio de un debate en el Congreso, uno de sus opositores lo llamó "hijo de esclavos" 58 . A Daniel Reyes le notificaron la existencia de fronteras raciales en Colombia en 1888, cuando se desempeñaba como secretario privado del presidente Rafael Núñez. En esa oportunidad, desde un diario bogotano, representaron el matrimonio de Núñez y Soledad Román a través de una caricatura. En la misma, según relata Román en sus memorias, aparecía ella "en trance de dar a luz a un negrito", pues, "Daniel Reyes, secretario entonces de la presidencia, es moreno" 59 .

La notable presencia que lograron varios negros y mulatos en el mundo intelectual y político de Cartagena y Colombia durante la primera mitad del siglo XX, también llevó a que miembros de la elite blanca hicieran uso de insultos raciales para cuestionar su presencia en los diversos cargos de representación. El médico negro Manuel Francisco Obregón, cuando ocupó por vez primera el cargo de representante a la Cámara (1912), fue objeto de agravios raciales. Desde el periódico La Unidad, el congresista conservador Laureano Gómez expresó que los "modales jayaneses" de Obregón en los debates que realizaba en el Congreso se explicaban por su temperamento racial ${ }^{60}$. A medida que la presencia de sectores negros y mulatos fue siendo más visible en la vida política de la Cartagena, miembros de élite blanca sentenciaron que la política había pasado a ser una "merienda de negros", expresión usada para indicar que la política se había convertido en un desorden total gracias a la notable presencia de los afrodescendientes en ese terreno ${ }^{61}$.

¿Cómo reaccionaron los sectores negros y mulatos a los insultos y agravios raciales y qué términos utilizaron para defender su presencia en los cargos de representación

\footnotetext{
${ }^{57}$ Núñez, Rafael, Op Cit., p. 56.

${ }^{58}$ Robles, Luis Antonio. Sombra y luz. Con la sombra en la epidermis y la luz en el alma (Bogotá: Universidad del Rosario, 2010), pp. 166-67.

${ }^{59}$ Lemaitre, Daniel. Soledad Román de Núñez. Recuerdos (Bogotá: Antares Limitada, 1988), p. 127.

${ }^{60}$ AHC, "La Época y la raza", El Mundo Nuevo, 4 de octubre de 1912.

${ }^{61}$ AHC, "Editorial”, El Luchador, 22 de octubre de 1921.
} 
política e intelectual? Los esfuerzos sistemáticos que se han realizado para entender el comportamiento político de los sectores afrodescendientes en el orden socio-racial colombiano, han estado marcados por explicar la no existencia de movimientos políticos racialmente definidos en el país. Insistentemente, sociólogos, antropólogos, e historiadores, independientemente del periodo de la República que estén analizando, se han preguntado por qué los habitantes negros de Colombia, a diferencia de sus pares afro-americanos, no organizaron poderosos movimientos raciales y se movilizaron colectivamente para lograr la igualdad racial ${ }^{62}$. Otros, sin abandonar esta primera perspectiva, han concentrado sus esfuerzos en señalar el deseo de estos profesionales y políticos negros por imitar los gustos de sus pares blancos, o en determinar el grado de conciencia racial de las mismos ${ }^{63}$.

Estas aproximaciones, aunque han permitido entender las dinámicas de desigualdad y discriminación racial que han caracterizado a Colombia, así como los procesos de diferenciación social que existían entre estos afrodescendientes con formación profesional y el grueso de la población negra y mulata, han avanzado poco en la reconstrucción de los discursos utilizados por los mencionados políticos y profesionales para lidiar con este orden socio-racial.

Historiadores que han analizado las relaciones raciales en Brasil y Cuba detectaron un problema historiográfico similar -en buena parte- de la literatura de los años setenta y ochenta del siglo XX. Para autores como George Reid Andrews y Alejandro de la Fuente, parte de la explicación tiene que ver con el hecho de que la primera perspectiva, al tiempo que considera la movilización colectiva como único mecanismo legítimo para cuestionar las desigualdades raciales, se concentra en explicar lo que los afrodescendientes fallaron en hacer y no en lo que realmente hicieron ${ }^{64}$. Y la segunda perspectiva, según la historiadora Paulina Alberto, deja poco espacio para contextualizar las vacilantes posiciones de negros y mulatos a la luz de su capacidad para leer las oportunidades y constreñimientos que le imponían los contextos políticos en los cuales actuaban ${ }^{65}$.

Los citados historiadores han ofrecido variantes interpretativas para repensar estas perspectivas de análisis. Confrontando el primer esquema interpretativo, el profesor George Reid Andrews sugiere que, en vez de concentrarnos en lo que no hicieron o

\footnotetext{
${ }^{62}$ Helg, Aline. Liberty and Equality in Caribbean Colombia, 1770-1835 (Chapel Hill: University of North Carolina Press, 2004); Wade, Peter. Blackness and Race Mixture. The Dynamics of Racial Identity in Colombia (Baltimore: Johns Hopkins University Press, 2003); Kronus, Sidney y Solaun, Mauricio. Discrimination without Violence: Miscegenation and Racial Conflict in Latin America (New York: John Wiley and Sons, 1973).

${ }^{63}$ Cunin, Elisabeth. Identidades a flor de piel (Bogotá: ICANH, Universidad de Los Andes, 2005).

${ }^{64}$ De La Fuente, Alejandro. A Nation for All. Race, Inequality and Politics in Twentieth Century Cuba (Chapel Hill: University of North Carolina Press, 2001); Andrews, George Reid. "Workers, Soldiers, Activists: Black Mobilization in Brazil and Spanish America, 1800-2000", en Estudios Interdisciplinarios de América Latina y el Caribe, núm.19, 2008, pp. 11-33.
}

${ }^{65}$ Alberto, Paulina, Op Cit., p. 10. 
dejaron de hacer los sectores afro-latinoamericanos, debemos reconstruir lo que dijeron e hicieron ${ }^{66}$. Y el historiador Alejandro de La Fuente, analizando el comportamiento de los afrocubanos durante la primera república, sugiere que la experiencia del Partido Independiente de Color, (partido político creado en 1908 y compuesto exclusivamente por sectores afrodescendientes), fue solo uno de los mecanismos utilizados por los afrocubanos para materializar la promesa de la igualdad racial. En Cuba, al igual que sucedió posteriormente con el Partido Autóctono Negro de Uruguay y el Frente Negra Brasileira, los sectores afrodescendientes fueron más proclives a vincularse a movimientos multirraciales y no a colectividades políticas racialmente definidas ${ }^{67}$. Finalmente, la referenciada Paulina Alberto, cuestionando la segunda perspectiva de análisis, plantea que solo reconstruyendo los propios términos que utilizaron los profesionales afrodescendientes podemos entender a través de qué discursos reclamaron un lugar en la vida local, regional y nacional ${ }^{68}$.

Estas observaciones metodológicas e interpretativas cobran mayor importancia en un país como Colombia donde, al menos hasta 1930, sus habitantes negros y mulatos no organizaron movimientos políticos a partir de criterios raciales para cuestionar las desigualdades raciales. Incluso, experiencias como las de los impopulares partidos políticos racialmente definidos que surgieron en Cuba, Uruguay y Brasil no hicieron parte del repertorio de acciones utilizadas por los sectores afrodescendientes en el marco de la Hegemonía conservadora. ¿Por qué seguir analizando su comportamiento político durante el siglo XIX y buena parte del siglo XX a la luz de las experiencias de sus pares afro-americanos? Los mecanismos y discursos que los afrodescendientes utilizaron para lidiar con el orden socio-racial en el cual estaban actuando en el tránsito del siglo XIX al XX hay que establecerlos a través de los procesos históricos que marcaron sus realidades políticas. Las guerras civiles que tuvieron lugar a lo largo del siglo XIX, en las que sectores negros y mulatos fueron protagonistas centrales, dieron forma a sus términos de inclusión. En efecto, a la hora de reclamar un trato igualitario, algunos evocaron la participación de sus antepasados en las luchas por la independencia. "[...]Verdad es que soy negro, pero esta sangre se oreó al sol en los campos de batalla en donde mis antepasados, cuyos huesos blanquean en las murallas de Cartagena, sacrificaron sus vidas para dar libertad a muchos blancos [...] de color, pero negros de conciencia", señaló Luis “el negro" Robles cuando recibió insultos raciales en las sesiones del Congreso en $1883^{69}$.

La conmemoración del centenario de la independencia de Cartagena (11 de noviembre de 1911) sirvió de catalizador para que la evocación de la decisiva participación de negros y mulatos en las guerras de independencia siguiera siendo utilizada como lenguaje para reclamar derechos y tomar parte activa en la vida política. En 1913, Manuel Francisco Obregón, en el marco de los cuestionamientos que le hizo Laureano

\footnotetext{
${ }^{66}$ George Reid Andrews hace buen uso de esa perspectiva en su influyente texto Afro-Latin America, 1800-2000 (New York: Oxford University Press, 2004).

${ }^{67}$ Andrews, George Reid, Op Cit., pp. 128-132.

${ }^{68}$ Alberto, Paulina, Op Cit., p. 10.

${ }^{69}$ Robles, Luis Antonio, Op Cit., p. 167.
} 
Gómez por su designación como gobernador, rememoró el papel decisivo que jugaron los artesanos del barrio de Getsemaní en la declaratoria absoluta de la independencia de Cartagena el 11 de noviembre de 1811:

La ciudad heroica rememora el pasado y recuenta sus glorias, se concentra en sí misma y destaca en el claroscuro de un cuadro remoto la figura imponente de aquella muchedumbre que viene de Getsemaní, se reúne en esta plaza, se detiene ante este mismo palacio, y ardorosa e intrépida, exige de (sic) la junta suprema proclame, por modo absoluto, la emancipación firme y rotunda ${ }^{70}$.

La formación profesional lograda y la idea de mérito asociada a la misma, se convirtieron en otra herramienta utilizada por varios profesionales negros y mulatos para criticar las desigualdades raciales en una sociedad que se declaraba democrática. El discurso de la educación, al tiempo que legitimaba la elegibilidad de los sectores afrodescendientes para los cargos de representatividad política, servía como arma para cuestionar las valoraciones raciales como criterios de distinción social. "Una esmerada educación, los naturales talentos, y una buena dosis de ilustración [...] debieran ser las cualidades que la inexorable ley moral reclamara en prendas para aquellos que quisieran perpetuar los ancestrales signos distintivos de un pueblo", señaló el médico negro Eduardo Miranda Fuentes a comienzos del siglo $\mathrm{XX}^{71}$.

La defensa del discurso de la ciudadanía por parte de profesionales y políticos afrodescendientes, como lo he descrito en otros artículos, fue determinante para cuestionar las barreras raciales que tuvieron que enfrentar ${ }^{72}$. Defendieron su condición de ciudadanos para reclamar su igualdad ante sectores que buscaban establecer como naturales ciertas jerarquías raciales. Como lo expresaron desde el periódico El Verbo, días después de que Manuel Francisco Obregón fue agraviado racialmente por Laureano Gómez, “[...] del esclavo surgió el siervo y el ciudadano bien pronto y a su lado la unidad de leyes, la igualdad de deberes y derechos [...] libre es el hombre y libre su amor y su conciencia ${ }^{73}$. No queda duda, entonces, que profesionales y políticos negros y mulatos adelantaron debates sobre las virtudes republicanas en un intento por desplazar las jerarquías raciales como elementos determinantes de las lógicas de inclusión social.

\section{Conclusión}

El estudio de la trayectoria de este conjunto de profesionales y políticos negros y mulatos permite repensar algunas premisas que a priori asumimos sobre raza y

\footnotetext{
${ }^{70} \mathrm{BBC}$, “Alocución del gobernador del Departamento de Bolívar", Gaceta Departamental de Bolívar, 14 de noviembre de 1913.

${ }^{71}$ AHC, “Doctor Manuel Dávila Flórez”, La Época, 21 de julio de 1913.

${ }^{72}$ Flórez Bolívar, Francisco Javier. “¿Hijos de la barbarie o de la ciudadanía?: negros y mulatos en el marco del primer centenario de la independencia de Cartagena, 1911-1941”, en Mosquera, Claudia; Lao Montes, Agustín y Rodríguez, Cesar Mauricio (eds.), Debates sobre ciudadanía y políticas raciales en las Américas negras (Cali: Universidad del Valle, 2010), pp. 542-570.

${ }^{73}$ AHC, "Lo que se estanca se pudre", El Verbo, 26 de septiembre de 1913.
} 
política durante la Hegemonía conservadora. La imagen de cincuenta años de dominio conservador caracterizados por la ausencia de liderazgos de personas de este origen racial no se corresponde con el accionar de un grupo de negros y mulatos que a través de la educación y la participación en las guerras civiles de finales del siglo XIX irrumpieron en la vida política y académica a nivel local, regional y nacional. El cuadro de pleno control conservador construye una visión estática sobre la compleja realidad política de este período, ocultando el dinamismo que procesos como las guerras civiles y la irrupción de los sectores profesionales y obreros le imprimieron a la vida política colombiana en las tres escalas previamente mencionadas.

¿La notable presencia política e intelectual que consiguieron sectores negros y mulatos durante la Hegemonía conservadora fue una dinámica exclusiva de Cartagena? Recientes trabajos sugieren que no. Por ejemplo, la historiadora Sharika Crawford, en un sistemático y bien pensado estudio sobre los esfuerzos que hicieron los gobiernos conservadores entre 1880 y 1930 por continentalizar las islas de San Andrés y Providencia, reconstruye las respuestas que los habitantes de ambas islas utilizaron para defender sus prácticas culturales frente a los mecanismos implementados por el Estado para lograr tal propósito. Crawford, a partir de un detallado análisis de las dinámicas locales, regionales y nacionales, destaca la existencia de un grupo de afrodescendientes, cuyo liderazgo fue central tanto en la defensa de la autonomía de San Andrés y Providencia frente al Departamento de Bolívar, como en la construcción de unas visiones propias de ciudadanía e identidad. Sugiere que este grupo no definió su identidad en términos de una lengua (español), una religión (catolicismo) y un ancestro común (hispánico), como lo propusieron los gobiernos de la Hegemonía conservadora. Los líderes afrodescendientes de San Andrés construyeron su identidad a través de la reafirmación de discursos que destacaban su pertenencia y lealtad a Colombia, así como su deseo de participar y tomar parte en los asuntos de la vida política nacional ${ }^{74}$. Una reciente investigación que realicé sobre las disputas que adelantaron sectores negros y mulatos de las costas Pacíficas y Caribe por materializar el ideal de igualdad en el tránsito del siglo XIX al XX también muestra la existencia de un significativo grupo de afrodescendientes que jugó un papel central en la trayectoria económica, política e identitaria de ambas regiones ${ }^{75}$.

El cuadro que hemos construido sobre los liderazgos logrados por sectores negros y mulatos entre 1885 y 1930 , entonces, parece provenir de los focos de análisis y de los sujetos históricos que hemos privilegiado. Nuevos estudios que exploren el accionar y los discursos de estos profesionales y políticos afrodescendientes en otros contextos pueden ayudarnos a ampliar las visiones que poseemos de la Hegemonía conservadora ¿El dinamismo político que caracterizó a los sectores negros y mulatos de Cali y el Cauca en general durante el liberalismo radical se diluye durante toda la Hegemonía

\footnotetext{
${ }^{74}$ Crawford, Sharika. "Under the Colombian Flag: Nation-Building on San Andrés and Providence Islands, 1886-1930”, (tesis doctoral), University of Pittsburgh, 2009.

${ }^{75}$ Flórez Bolívar, Francisco Javier. En sus propios términos: negros y mulatos y las luchas por la igualdad en Colombia, 1885-1947, (tesis doctoral), University of Pittsburgh, 2016.
} 
conservadora? ¿Qué grado de representatividad (local, regional, nacional) lograron políticos negros y mulatos vinculados al Partido Conservador durante los cincuenta años de gobierno de esta colectividad? ¿Qué dinámicas políticas y raciales generaron profesionales y políticos afrodescendientes que dejaron sus lugares de orígenes y se ubicaron en ciudades como Pasto, Cali, Popayán, Medellín y/o Bogotá? Tal vez en cada uno de estos centros urbanos, al igual que en Cartagena, los profesionales y políticos afrodescendientes fueron una minoría. El hecho de que sean una minoría, sin embargo, no invalida su condición de sujetos históricos susceptibles de análisis ni su incidencia en los debates sobre raza y representatividad política que tuvieron lugar entre 1885 y 1930 . Más bien, hay que explorar las posibilidades de análisis que se abren a partir del accionar de estos sectores que incidieron en la realidad política que se vivió durante la Hegemonía conservadora.

\section{Fuentes}

\section{Fuentes Primarias}

\section{Archivos}

Archivo Histórico de Cartagena (AHC).

Archivo del Congreso (AC).

Biblioteca Bartolomé Calvo.

Biblioteca Nacional de Colombia.

\section{Prensa}

Anales del Concejo, Cartagena, 1937, 1938.

Diario de la Costa, Cartagena, 1920, 1923.

Diario Oficial, Bogotá, 1914.

El Autonomista, Cartagena, 1912.

El Debate, Cartagena, 1925.

El Esfuerzo, Cartagena, 1923.

El Humanitario, Cartagena, 1923.

El Imparcial, Cartagena, 1911. 
Re-visitando la Hegemonía conservadora: raza y politica en Cartagena (Colombia)...

El Liberal, Cartagena, 1910, 1911, 1919.

El Luchador, Cartagena, 1921, 1923, 1930.

El Mercurio, Cartagena, 1929.

El Mundo, Cartagena, 1935.

El Mundo Nuevo, Cartagena, 1912.

El Penitente, Cartagena, 1910.

El Porvenir, Cartagena, 1915, 1918,1928.

El Republicano, Cartagena, 1912.

El Verbo, Cartagena, 1913.

Gaceta Departamental de Bolívar, Cartagena, 1913.

La Constitución, Cartagena, 1916.

La Discusión, Cartagena, 1915.

La Época, Cartagena, 1912, 1913, 1917, 1918, 1920.

La Patria, Cartagena, 1923, 1929.

La Verdad, Cartagena, 1913.

El Porvenir, Cartagena, 1899.

Gaceta de Bolivar, Cartagena, 1881, 1892.

Registro de Bolivar, Cartagena, 1895.

Anales de la Cámara de Representantes, Bogotá, 1880-1930.

Anales del Senado, Bogotá, 1880-1930.

\section{Fuentes secundarias}

\section{Libros}

Alberto, Paulina. Terms of Inclusión. Black Intellectuals in Twentieth-Century Brazil. Chapel Hill: University of North Carolina Press, 2015. 
Andrews, George Reid. Blackness in the White Nation: A History of Afro-Uruguay. Chapel Hill: University of North Carolina Press, 2010.

Andrews, George Reid. Afro-Latin America, 1800-2000. New York: Oxford University Press, 2004.

Andrews, George Reid. Blacks and Whites in Sao Paulo, Brazil, 1888-1988. Madison: University of Wisconsin Press, 1991.

Angulo, Álvaro. Aspectos sociales y políticos de Cartagena de Indias. Siglos XVI y XIX. Barranquilla: Antillas, 2001.

Appelbaum, Nancy. Muddied Waters: Race, Region and Local History in Colombia, 1846-1948. Durham: Duke University Press, 2003.

Arias, Julio. Nación y diferencia en el siglo XIX colombiano. Orden nacional, racialismo y taxonomías poblacionales. Bogotá: Universidad de los Andes, 2005.

Coniff, Michael. Black Labor on a White Canal. Panama, 1904-1981. Pittsburgh: University of Pittsburgh, 1985.

Corrales, Manuel Ezequiel. Efemérides y anales del Estado Soberano de Bolívar. Cartagena: Gobernación de Bolívar/Instituto Internacional de Estudios del Caribe/ Carlos Valencia editores, 1999.

Cunin, Elisabeth. Identidades a flor de piel. Bogotá: ICANH, Universidad de Los Andes, 2005.

Devis Echandía, Julián. La ciudad vencida. La Cartagena de ayer, la Cartagena de hoy. Bucaramanga: Gómez y Páez, 1937.

De La Fuente, Alejandro. A Nation for All. Race, Inequality and Politics in Twentieth Century Cuba. Chapel Hill: University of North Carolina Press, 2001.

Geler, Lea. 2010. Andares negros, caminos blancos: Afroporteños, Estado y nación. Argentina a fines del siglo XIX. Rosario: Prohistoria, 2010.

Helg, Aline. Liberty and Equality in Caribbean Colombia, 1770-1835. Chapel Hill: University of North Carolina Press, 2004.

Kronus, Sidney y Solaun, Mauricio. Discrimination without Violence: Miscegenation and Racial Conflict in Latin America. New York: John Wiley and Sons, 1973.

Lemaitre, Danel. Soledad Román de Núñez. Recuerdos. Bogotá: Antares Limitada, 1988. 
Re-visitando la Hegemonía conservadora: raza y politica en Cartagena (Colombia)...

Manrique Fernández, Miguel. Fragmentos históricos de San Jacinto, Bolívar. Cartagena: Alpha editores, 2015.

Maza, Edwin. Facultad de Medicina de la Universidad de Cartagena. Su historia. Cartagena: Universidad de Cartagena, 1998.

Múnera, Alfonso. Tiempos difíciles. La república del siglo XIX: una ciudadanía incompleta. Bogotá: Pluma de Mompox, 2011.

Múnera, Alfonso. El fracaso de la nación. Región, raza y clase en el Caribe colombiano, 1717-1810. Bogotá: Banco de la República/Ancora Editores, 1998.

Múnera Ruiz, Leopoldo y Cruz, Edwin (eds.). La Regeneración revisitada. Pluriverso y hegemonía en la construcción del Estado-nación en Colombia. Medellín: La Carreta Editores, 2011.

Núñez, Rafael. La reforma política. Medellín: Editorial Lealon, 1994.

Otero, Samuel. Cien costeños meritorios. Tomo I. Cartagena: Imprenta departamental, 1918.

Palacios, Marco. Entre la legitimidad y la violencia. Colombia 1875-1994. Bogotá: Editorial Vitral, 1998.

Pérez, Amada. Nosotros y los otros. Las representaciones de la nación y sus habitantes, 1880-1910. Bogotá: Universidad Javeriana, 2015.

Martínez Pinzón, Felipe. Una Cultura de invernadero: Trópico y civilización en Colombia (1808-1928). Madrid y Frankfurt: Iberoamericana-Vervuert, 2016.

Robles, Luis Antonio. Sombra y luz. Con la sombra en la epidermis y la luz en el alma. Bogotá: Universidad del Rosario, 2010.

Uribe-Urán, Víctor Mario. Honorable lives: Lawyers, Family and Politics in Colombia, 1750-1850. Pittsburgh: University of Pittsburgh Press, 2000.

Valdelamar, Juan y Gutiérrez, Juan. Getsemaní. Oralidad en atrios y pretiles. Cartagena: Litografías del Mar, 2005.

Wade, Peter. Blackness and Race Mixture. The Dynamics of Racial Identity in Colombia. Baltimore: Johns Hopkins University Press, 1993.

Zabaleta, Horacio. Réquiem por un viejo hospital. Bogotá: Tercer Mundo, 1974. 


\section{Capítulos de libro}

Flórez Bolívar, Francisco Javier. “¿Hijos de la barbarie o de la ciudadanía?: negros y mulatos en el marco del primer centenario de la independencia de Cartagena, 19111941”, en Mosqueda, Claudia; Lao Montes, Agustín y Rodríguez, Cesar Mauricio, Debates sobre ciudadanía y políticas raciales en las Américas negras. Cali: Universidad del Valle, 2010.

Grossberg, Lawrence. "Identidad y estudios culturales", en Hall, Stuart y Du Gay, Paul (eds.), Cuestiones de identidad. Buenos Aires: Amorroru editores, 2003.

Melo, Jorge Orlando. "La república conservadora", en Arrubla, Mario (ed.), Sobre historia y política. Bogotá: Siglo Veintiuno, 1978.

Grossberg, Lawrence. "Etnia, región y nación: el fluctuante discurso de la identidad (notas para un debate)", en Jimeno, Myrian, et al. (eds.), Identidad: Memorias del simposio identidad étnica, identidad regional, identidad nacional. Bogotá: ICANHColciencias-FAES, 1989.

Wade, Peter. "Identidad", en Serge, Margarita; Suaza, María Cristina y Pineda, Roberto (eds.), Palabras para desarmar. Bogotá: ICANH, 2002.

\section{Artículos de revista}

Álvarez Jiménez, Jairo. "Las caras diversas de las guerras civiles en el Bolívar Grande (Colombia, siglo XIX)", en Anuario de Historia Regional y de las Fronteras, vol. XIX, núm. 2, (julio-diciembre), 2014, pp. 529-553.

Andrews, George Reid. "Workers, Soldiers, Activists: Black Mobilization in Brazil and Spanish America, 1800-2000”, en Estudios Interdisciplinarios de América Latina y el Caribe, núm. 19 2008, pp. 11-33.

Flórez Bolívar, Francisco Javier. "Iluminados por la educación: los ilustrados afrodescendientes del Caribe colombiano a comienzos del siglo XX", en Cuadernos de Literatura del Caribe e Hispanoamérica, núm. 9, 2010, pp. 35-58.

Posada, Eduardo. "Limits of Power. Elections under the Conservative Hegemony in Colombia, 1886-1930", en Hispanic American Historical Review, vol. LXXVII, núm. 2, 1997, pp. 245-279.

Rhenals, Ana Milena. "Tejiendo la red: circuitos comerciales, inmigrantes siriolibaneses y empresarios nacionales en el Caribe colombiano y el Atrato (1880-1930)", en Historia y Espacio, núm. 37, 2011, pp. 189-212. 
Re-visitando la Hegemonía conservadora: raza y politica en Cartagena (Colombia)...

Sanders, James. "Ciudadanos de un pueblo libre": liberalismo popular y raza en el suroccidente de Colombia en el siglo XIX, en Historia Crítica, núm. 38, 2009, pp. 172-203.

Solano, Sergio Paolo. "Política, religión e intelectuales en el Caribe Colombiano durante la Regeneración (1886-1899)”, en Historia Caribe, núm. 4, 1999, pp. 43-60.

\section{Tesis}

Crawford, Sharika. Under the Colombian Flag: Nation-Building on San Andrés and Providence Islands, 1886-1930, (tesis doctoral), University of Pittsburgh, 2009.

Flórez Bolívar, Francisco Javier. En sus propios términos: negros y mulatos y sus luchas por la igualdad en Colombia, 1885-1947, (tesis doctoral), University of Pittsburgh, 2016.

Flórez Bolívar, Francisco Javier. Beyond the White Republic: Afro-descendant Elites, Race and Citizenship in Cartagena (Colombia) 1903-1945, (tesis de maestría), University of Pittsburgh, 2011.

Leal, Claudia. Black Forests: The Pacific Lowlands of Colombia, 1850-1930, (tesis doctoral), University of California, 2004.

McGraw, Jason. "Neither Slaves nor Tyrants": Race, Labor and Citizenship in Caribbean Colombia, 1850-1930, (tesis doctoral), University of Chicago, 2006.

Malkun, William. Educación y política en el Estado Soberano de Bolívar 1857-1885, (tesis de maestría), Universidad de Cartagena-Universidad Tecnológica y Pedagógica de Tunja, 2008. 